\title{
Neglect: An Interpretative Phenomenological Investigation of Senior Care Professionals' Experiences Working with Neglected Adolescents
}

\author{
Ehab W. Hermena ${ }^{1}$, Felicity L. Bishop ${ }^{2}$ \\ ${ }^{1}$ Cognition and Neuroscience Research Laboratory, Department of Psychology, Zayed University, \\ Dubai, UAE \\ Ehab.Hermena@zu.ac.ae \\ ${ }^{2}$ Department of Psychology, University of Southampton, UK \\ F.L.Bishop@soton.ac.uk
}

\begin{abstract}
This study explores the phenomenon of neglect in adolescence as seen by senior care professionals. Five senior professionals took part in semi-structured interviews. We used an interpretative phenomenological approach to identify idiographic themes and superordinate themes that were common across participants. Reflexive bracketing and unbracketing were explicitly integrated into the interpretative processes. In our participants' experiences, neglect extends as a spectrum; perpetuates itself as a cycle; and can be particularly difficult to detect in adolescence because of certain societal and professional factors. For our participants, neglect in adolescence is situated in a complex web of related factors including family stability, parental mental health and parenting attitudes. Given the common co-occurrence of the concepts of abuse and neglect in academic and professional literature, we sought to establish how our participants experienced neglect in relation to abuse. By incorporating a drawing task into our phenomenological interviews, we obtained revealing visual metaphors of this relationship between neglect and abuse. Future research implications are discussed.
\end{abstract}

Key words: IPA, phenomenology, reflexivity, bracketing, reinterpretation, double hermeneutic, neglect, abuse

Investigations into poor child-rearing conditions have traditionally focused on linking phenomena like abuse, neglect, maltreatment and deprivation with later negative consequences for young people. It has long been established that neglected and maltreated youngsters find it hard to form or develop social relationships with peers (Howes, \& Espinosa, 1985), and have difficulty coping with stressful life events (Harkness, Bruce, \& Lumley, 2006; Harkness, Lumley, \& Truss, 2008; Sullivan, Fehon, Andres-Hyman, Lipschitz, \& Grilo, 2006). Children who experience emotional, physical or sexual abuse are more likely to act violently on romantic dates as adolescents (Wekerle,
Leung, Wall, MacMillan, Boyle, Trocme, \& Waechter, 2009). They are also more likely to display other types of maladjusted behaviours, or develop mental health problems as well as risky health habits including alcohol use disorders (see Clark, Thatcher, \& Maisto, 2005; also Fergusson, Boden, \& Horwood, 2008; Smith, Ireland, \& Thornberry, 2005). Additionally, maltreated or abused adolescents are more likely to become teenage parents, who in turn neglect or abuse their children (e.g. Becker-Lausen \& Rickel, 1995; George, Harden, \& Lee, 2008; Zuravin \& Di Blasio, 1992). Ultimately, neglect and abuse may result in a young person's death (Jenny \& Isaac, 2006). While establishing the harmful 
consequences of neglect, abuse and other forms of poor child-rearing conditions, these investigations offer only limited insight into the nature of these particular phenomena and of their unique contributions towards negative developmental outcomes. Indeed, academic and professional publications simply list neglect alongside other poor child-rearing phenomena, particularly abuse, when describing disadvantageous developmental conditions, developing assessment tools, or proposing new practice policies (e.g. Crowley, Mikulich, Ehlers, Hall, \& Whitmore, 2003; DCSF, 2010; Hall \& Williams, 2008; Swenson, Schaeffer, Henggeler, Faldowski, \& Mayhew, 2010). Detailed descriptions of these phenomena are rarely incorporated. This research thus set out to explore the nature and some manifestations of adolescence neglect as a phenomenon.

Recent professional and governmental interest in neglect in England has culminated in the following definition proposed by the UK government:

Neglect is the persistent failure to meet a child's basic and/or psychological needs, likely to result in the serious impairment of the child's health or development. Neglect may occur during pregnancy as a result of maternal substance abuse. Once a child is born, neglect may involve a parent or carer failing to: provide adequate food, clothing and shelter (including exclusion from home or abandonment); protect a child from physical and emotional harm or danger; ensure adequate supervision (including the use of inadequate care-givers); ensure access to appropriate medical care or treatment. It may also include neglect of, or unresponsiveness to, a child's basic emotional needs (HM Government, 2006, p. 38, emphasis added)
This definition was subsequently cited in professional literature (e.g. Hicks \& Stein, 2010) and is widely disseminated amongst professionals. However, critical evaluations of this definition are scant. Importantly, we felt that the way this definition summarises lived experiences of neglect requires a little more exploration and unpacking.

Three groups can be identified who might usefully contribute to an exploration of the lived experience of neglect in adolescence: the neglected adolescents themselves; the adults who neglect them; and the professionals who are closely involved with these parties. In order to access the first two groups, we would need the help of professionals and would be guided by the definitions and criteria employed by these professionals to identify "neglect". We therefore decided to focus on the professionals themselves, as individuals who are actively involved in interpreting the available definition of neglect and using it to label certain child-rearing situations and phenomena. To understand what adolescent neglect means to care professionals we chose interpretative phenomenological analysis (e.g., Thomas \& Pollio, 2002) as best-suited for addressing such questions as: how do these professionals see neglect? What is neglectwhat does it look like in their experiences? How do professionals interpret their experiences of dealing with neglect in adolescence? We appreciate that to some, a focus on the professionals' experiences of neglect (rather than the neglected adolescents' experiences) may not fit the traditional focus of phenomenological investigations where research explores "existential matters of considerable importance for the participant...[t]hese matters are transformative, bringing change and demanding reflection and (re)interpretation for the individuals concerned" (Eatough \& Smith, 2008, p.186). Yet, and although adolescence neglect is less of an existential matter to our participants than 
to their clients, our carefully-selected participants regard their experiences dealing with neglect as of "considerable importance" and through reflection, reinterpretation, and fully engaging with the phenomenon of neglect as feeling and empathetic human beings, they transform and are transformed by these experiences, so we feel no methodological mismatch. We consider Rytterström, Cedersund, and Arman's (2009) phenomenological-hermeneutic investigation which tried to understand and develop the concept of a caring culture through interpreting the lived experiences of hospital nurses to be a good precedent for our investigation.

Our investigation thus aimed at learning more about the nature and manifestations of neglect in adolescence, to address what we identified as a gap in our current knowledge. We explored this phenomenon as it presented itself to a group of senior care professionals, that is, we hoped to see it through interpreting their experiences in an IPA investigation.

\section{Method}

\section{Design}

In all stages of this investigation we adopted an interpretative phenomenological approach, guided by the philosophy of Merleau-Ponty (e.g., 1962). We followed the analytic processes of Interpretative Phenomenological Analysis (IPA) as described by Langdridge (2007; also Smith \& Osborn, 2003; Thomas \& Pollio, 2002). As further described below, we deployed empathetic and critical questioning and prompting in collecting data in the phenomenological semi-structured interviews conducted with all participants. Our analysis also reflects this layered, empathetic then critical, approach to reading and interpretation. We aimed to create a double hermeneutic narrative, that is, a coherent interpretation of the participants' interpretations of their life experiences dealing with adolescence neglect.

As discussed above, a good understanding of neglect entails defining its boundaries and potential relationship with abuse. To achieve this, we incorporated in our interviews a rarely-used interpretative tool: We asked participants to express as a drawing or a diagram any relationship that they felt existed between neglect and abuse. We then asked them to comment on their diagrams. In asking our participants to capture and interpret their experiences of possibly complex and confusing phenomena through drawings and diagrammatic output, we subscribed to the phenomenological philosophies of Shapiro (1985) and Van Manen (1990). Simply put, if creating images is the primary function of language-based metaphors, and these are greatly valued in phenomenology, then diagrammatic interpretations also have a place in phenomenology. Diagrams and images may convey meanings and interactions between essential aspects of a phenomenon - they may be clearer in our minds before we produce them as words (see also Polkinghorne, 1989). Indeed, drawing visual metaphors to capture aspects of human experiences has a long tradition in therapeutic work and literature, particularly when the issues, relations, or experiences being explored are of sensitive, complex or confusing nature (e.g. Lev-Wiesel, 1998; Ramm, 2005). Ramm captured the phenomenological significance of drawing thus: "Drawing is a fundamental human activity which expresses and intensifies our experience of existing in the world" (p. 63). To our knowledge, only one other phenomenological investigation utilised this technique in exploring children's thoughts about the environment (Alerby, 2000).

Ethical and governance approval from the University of Southampton, UK, were sought and granted. 


\section{Participants}

Five senior professionals made up the small homogenous sample required for IPA (Eatough \& Smith, 2008; Langdridge, 2007; Smith \& Osborn, 2003). We sought participants with extensive experience in positions to interpret governmental policies, and impact upon service delivery ethos and practices. Thus we recruited participants who were at, or immediately below, managerial level and who had supervisory roles in relation to frontline professionals. Finally, and to ensure the relevance and authenticity of participants' experiences, we required that our participants have recent (within the last 3 years) casework hands-on experience, either directly or through supervising colleagues. Two participants were recruited from the statutory sector, three from the voluntary sector. At the time of conducting this research, the participants had between 9 and 20 years of experience working with disadvantaged children and adolescents $(M=$ 14.6).

The participants in their professional roles would typically support adolescents who are or are at high risk of offending, excluded from mainstream education, sexually exploited, homeless, engaged in alcohol or substance misuse, and/or abused. The type of support provided included working with young people or their families directly and indirectly through supervising case-workers, or sometimes, other involved agencies. In approaching these participants, we made an implicit assumption that they would have witnessed and dealt with instances of adolescence neglect through these experiences. Put differently, given that there are no agencies who purport to exclusively deal with cases of neglect, we assumed a link between being neglected as an adolescent, and falling into one of the above listed categories of service recipients.

\section{The Researchers}

This research was undertaken as part of EH's doctoral studies in educational psychology at the University of Southampton. EH conducted the interviews and led the analysis, supervised by FB.

We undertook existential bracketing (Gearing, 2004) throughout this project. Here, according to Thomas and Pollio (2002, p. 34), we place "within parentheses" any beliefs or attitudes, or what Gadamer (1960) described as "necessary prejudices," so that we become more open and ready to be led into the lifeworld and the experiences each participant is sharing. We acknowledge that bracketing these necessary prejudices can never be complete: We can never transcend these prejudices, or see or study the world without them, so long as we inhabit the physical bodies (Merleau-Ponty, 1962) and social, cultural and historical spheres we do. Furthermore, and as Thomas and Pollio explain, for us, bracketed material is "temporarily suspended, not banished... Bracketing is not a one-time event; it is a dynamic, ongoing process," (p. 33).

Following Thomas and Pollio (2002; also George \& Thomas, 2010; Rolls \& Relf, 2006), $\mathrm{EH}$ underwent a bracketing interview with FB, which was subsequently transcribed and analysed. EH extracted themes from this transcript which served to heighten the sensitivity of both authors to a number of EH's necessary prejudices, which included:

- EH expressed that as a scholar, his interest in the process and method of investigation was stronger than his interest in the phenomenon being investigated.

- EH approached the phenomenon, theoretically, with a degree of overconfidence and detachedness. In realising this, EH believed he was in danger of his attitude leading the participants to adopt the same stance: "I'll look and see what I see...I'll trust in the process and I'll try to 
do it rigorously and it's the best you can ask from a human [laughs]"

- As a professional, EH saw himself as an agent of a public services system which he described as "noble" and "civilised". Yet $\mathrm{EH}$ worried if this system can ever achieve its goal of serving and caring for vulnerable members, such as neglected adolescents, as this entails almost attempting to "replace...much more organic units of society like the family or the extended family". In this, EH believed himself greatly influenced by his cultural and socio-economic background, having been brought up outside the UK.

- EH was influenced by the psychological concept of "readiness" and felt that the system's success in providing support depends, to a large extent, on the readiness of problem owners to accept, and meaningfully engage with, the offered support.

- EH largely adopted the UK Government (2006, see above) definition of neglect, and believed that it uses the words "failing to..." accurately. However, he felt the definition was deficient as it fails to explicitly take into account the variables which may impact upon a parent's or an adult's ability to provide the necessary care for adolescents: "this 'failing to', [the definition] stop[s] short of...that's not clear to me or in the definitions I've come across: 'failing to' due to what?".

These reflections were used to inform a continuing and updateable bracketing process whereby EH recorded in a research diary updates, expansions and revisions of bracketed content. As bracketed materials were "temporarily suspended, not banished" the process of bracketing was completed by explicitly unbracketing some of the bracketed content into the analysis, interpretation and writing phases, rendering the process more transparent. For instance, when participants spoke of adolescents' engagement with the offered support in a manner which we felt was related to the concept of "readiness", this concept was explicitly mentioned in the text (see below) and we highlighted its link, in our view, to what the participant was saying. Bracketing and unbracketing were thus integral to our interpretative processes, not merely tools for reflexivity.

\section{Procedure}

We developed, piloted, and revised an interview topic guide. The initial questions were designed to elicit conversation about participants' professional roles and experiences. Subsequent questions asked participants to describe aspects of their sensory (what they heard or saw) and emotional experiences while dealing with adolescence neglect. Two questions were dedicated to exploring the relationship between neglect and abuse as participants interpret it, if they felt there was such a relationship. The first question required participants to produce a drawing or a diagram, while the second required them to verbally comment on their drawings. We prepared a set of neutral verbal prompts (e.g. you can use lines, figures, or draw a diagram) in case the participants found the task too challenging. In addition to the topic guide, layers of empathetic and suspicious, or critical, prompts (Eatough \& Smith, 2008; Langdridge, 2007) were employed in the conversations to aid the interpretative process. The spirit of exploring participants' making sense of their experiences, not the letter of the topic guide was adhered to in all interviews.

EH contacted the participants and upon expressing an interest in participating, they received, electronically, further information about the investigation. Face to face semistructured interviews were arranged, and 
written consent was obtained before each interview commenced. Each interview lasted about an hour and was audio-recorded.

A second written consent, which we termed dissemination consent, was obtained from all participants in a second meeting with $\mathrm{EH}$, where he shared with them how we used, and interpreted, their accounts. This additional consent was thought necessary for two reasons. Firstly, this investigation explores issues which are closely linked with the participants' own professional identities, thus we felt it appropriate for the participants to be the first to see and comment on the findings. Secondly, considering the participants to be our first audience, the quality-check for us would be if they could see what we saw by adopting our viewpoint (Thomas \& Pollio, 2002; see also Rytterström et al., 2009, p. 696, for similar approach). With minimal corrections, all participants recognised and expressed satisfaction with our interpretations and consented for us to disseminate this knowledge.

\section{Data Analysis}

We transcribed the interviews and read them a number of times. This reading was followed by an initial phase of empathic coding of the text where we sensitised ourselves to all the details and issues the participants shared with us. A more critical coding process followed, where we began the interpretative process to identify subthemes, which we later, through further interpretation, arranged into a table of main themes. We repeated these steps for all participants' transcripts; however, we used the table of themes and subthemes extracted from the first participant with the following participants' transcripts (e.g. Langdridge, 2007). We extended and modified this theme table with the addition and migration of new subthemes and themes, in response to each participant's account. We documented changes to the theme structure to maintain transparency.

When working to identify themes, we always considered potential links between what participants told us and the bracketed content described above. Furthermore, we also considered the value of making explicit any such links when reporting the findings. Whenever we felt that bracketed content may aid us in further building a clearer interpretation or in presenting a more vivid narrative, that content was unbracketed.

Finally, we produced a theme table for each participant, and a master theme table capturing the whole dataset. We used the latter in writing this article. This too was a dynamic process where the flow of the interpretative narrative was allowed to organically evolve and guide the final theme structure we present here. We prioritised those themes which best illustrate and illuminate this narrative over other themes which dealt with, for instance, more generic aspects of participants' professional roles like within-agency communication protocols or peer-supervision mechanisms. In addition to unbracketed content, we weaved into our narrative some of the participants' own words, phrases and sentences wherever we felt that these quotes would help to convey the meanings we were extracting and interpreting in fuller colour or with greater authenticity than our own words.

\section{Results}

Five themes are presented below and summarised in Table 1. We will be exploring how participants see neglect as a spectrum and as a self-perpetuating cycle. We will then describe how neglect can be difficult to detect, particularly for this age group (adolescence). Next we will explore the complex issues which surround the neglect and the relationship between neglect and abuse. Finally, we will discuss the participants' and 
researchers' emotional and professional responses to the topic of neglect.

\section{Neglect Extends as a Spectrum, and Perpetuates Itself as a Cycle}

Participants used two metaphors (spectrum and cycle) to describe neglect.

Table 1

Summary of Themes and Subthemes Extracted from Participants' Data

\begin{tabular}{|c|c|}
\hline Theme & Subtheme \\
\hline $\begin{array}{l}\text { Theme I: Neglect } \\
\text { Extends as a } \\
\text { Spectrum, and } \\
\text { Perpetuates Itself as a } \\
\text { Cycle }\end{array}$ & $\begin{array}{l}\text { 1.1 Neglect as a spectrum } \\
\text { 1.2 Neglect as multi- } \\
\text { levelled cycle }\end{array}$ \\
\hline $\begin{array}{l}\text { Theme II: The } \\
\text { Complexity of } \\
\text { Detecting Neglect }\end{array}$ & \\
\hline $\begin{array}{l}\text { Theme III: Issues and } \\
\text { Circumstances Linked } \\
\text { with Adolescence } \\
\text { Neglect }\end{array}$ & \\
\hline $\begin{array}{l}\text { Theme IV: Neglect } \\
\text { and abuse }\end{array}$ & $\begin{array}{l}4.1 \text { The relationship } \\
\text { between neglect and abuse } \\
4.2 \text { Neglect and abuse: } \\
\text { more visible means more } \\
\text { important? }\end{array}$ \\
\hline $\begin{array}{l}\text { Theme V: Dealing } \\
\text { with Neglect }\end{array}$ & $\begin{array}{l}\text { 5.1 The feeling } \\
\text { professionals } \\
5.2 \text { Matters of practice }\end{array}$ \\
\hline
\end{tabular}

\subsection{Neglect as a spectrum}

Working with neglected adolescents and their families, the participants described neglect as a "wide spectrum" (participant 1), at the "serious" end of which an adolescent would lack all basic care and attention (participants $3 \& 4$ ), whereas at the "lesser" end an adolescent may only lack less necessary things like "nice clothes" (participant 4).

The participants reported how they often deal with cases where varying levels of the lesser and more serious aspects of neglect are present. Poorly fed adolescents may also be "unkempt [and] dishevelled" (participant 4), and have very poor hygiene which may develop into health problems (e.g. participant 2). The participants see, or learn from supervised colleagues, that these adolescents often inhabit cramped environments where hygiene is "dramatically poor" (participant 1) and they have no personal space, as other neglected children and animals abound (participants 1, $3 \& 4$ ).

For our participants, the more serious end of the spectrum seems to extend in time in that it impacts on adolescents' present, as well as future, wellbeing. Participant 3 described a "distinct absence" of adults' interest in the present safety of an 11-year-old boy:

"He's quite little to be going swimming just on your own and wasn't any of 'what time are you going to be back?' or 'make sure you ring me on the way'...it's the attitude that 'he'll turn up sometime when he's hungry'."

This "distinct absence" of parental interest is also evident in neglecting adolescents' developmental needs including their emotional (participants 2, 3, \& 4), educational (participant 1) and physical health needs (participant 3). This, invariably, in the participants' experiences, places these adolescents at a continuous disadvantage: now, because they are neglected, and in the future because they are not being prepared for it:

You can see it...how they deal with things, they are just not able-I was trying to show a girl... how to pick up the phone to talk to someone about getting a job, and she just couldn't...no one has ever equipped her with those skills...very basic things that other teenagers just do (participant 4)

This notion links well with the cycle subtheme we present below. 
The participants pointed to another facet of the serious end of the neglect spectrum: Neglecting adults fail to instigate boundaries for adolescents. These adolescents thus seem to "just do as they please" (participant 1), which often includes placing themselves at greater risks of offending or exploitation.

\subsection{Neglect as multi-levelled cycle}

When dealing with neglect cases in the present, participants seemed to see neglect as a spectrum. The metaphor changed however as our conversations allowed them to adopt a broader perspective. When looking at their experiences from a more interpretative standpoint, the participants described how working with adolescence neglect, over time, feels like dealing with something that is cyclical in nature. On one level, participants see some neglected youth who grew up to become neglecting parents of their own offspring (participant 2). On another level, participants find themselves dealing with adolescents who need their support, yet through their prolonged experiences of neglect fail to accept support, or act in ways to avoid, or repel, the adults (participant 5). On both levels of the cycle, neglect perpetuates neglect.

We feel it beneficial to unbracket the concept of readiness here: perhaps these adolescents' lack of readiness to accept the care offered (Williams, Lindsey, Kurtz, \& Jarvis, 2001) contributes to perpetuating the cycle.

Critical prompting of participants revealed that in their interpretations, they do not feel adolescents are to blame (e.g. participant 2) even when they fail to accept the offered support, or act in ways to repel adults. Rather, they fully appreciate that the history of neglect makes these adult-repelling responses the "ingrained behaviours" of neglected adolescents (participant 3).

\section{The Complexity of Detecting Neglect}

Participants described linguistic, professional and societal factors which serve to complicate the detection of adolescence neglect. Despite participants seeing neglect extending and perpetuating itself in the lives of neglected adolescents, this neglect can be hard to detect: "if you asked a practitioner about physical abuse or sexual abuse...it's much easier, it's kind of there, but neglect, what is it?" (Participant 5, emphasis added).

To begin with, participant 2 explained, "it would be very unusual for a young person to come and say I'm being neglected, it's not part of people's vocabulary". And while neglect is certainly part of professionals' vocabulary, it can be hard to decide if it should be applied to certain cases. The reason for that is what we may interpret as a parenting spectrum in our participants' experiences, where, at one end there are uncaring parents, and at the other end there are "parents who have tried and tried and tried and [have] been worn down...we see [these parents] in tears because they can't reach the child" (participant 1). Here, to further amplify the voice of our participants, we unbracket the dissatisfaction expressed above with the UK Government (2006) definition of neglect. The participants' experiences clearly reflect that it is not sufficient to list neglectful behaviours and present them in a contextual vacuum: The family and parenting circumstances surrounding neglect need to be made explicit in any definition, particularly a definition intended to guide professionals' practice.

Another factor which adds to the complexity of detecting neglect in our participants' experience relates to the combination of how society at large sees adolescents, and how adolescents respond to being neglected. Participant 5 explains:

Adolescents are older [and] deemed to stand on their own two feet and make 
their own choices, more than a younger child...they can walk away...Now, their getting up and walking away often puts them in more risk

It is as if society finds it hard to grasp how adolescents can be victims of neglect. Even some professionals, being saturated with this culture, may, inadvertently, further burden disempowered and neglected adolescents with premature references to responsibilities, "choices" and "consequences to their actions" (participant 3). So, it seems that adolescents respond to neglect with layers of adultrepelling (see above) behaviours like rejecting help, offending, making bad choices (participants $1 \& 5$ ) and developing very low self-worth (participant 3) and "hopelessness" (participant 1). And this in turn complicates the detection of neglect as professionals must see through, and peel-off, these layers to reveal that an adolescent is actually experiencing neglect, rather than merely acting hopeless, hard-to-reach, or incapable of making good choices.

\section{Issues and Circumstances Linked with Adolescence Neglect}

Participants talked about complicated links between different indicators and facets of neglect. From the perspective our questions allowed us to acquire, it was clear that participants had developed understandings of neglect that involved multiple dependent and complex causal and contextual factors.

Prominent amongst these factors is parental alcohol or other substance dependence problems, including nicotine. In our participants' experiences, neglect becomes inevitable as these parents prioritise meeting their substance-related needs over meeting the adolescents' needs, especially if facing financial hardship (participants $1 \quad \& \quad 4$ ). Indeed, adolescents may "[become] young carers...for parents who are substance and alcohol users" (participant 1), which further deprives them from the nurturing they need. Similarly, parents with mental health problems are seen to have reduced capacity for care (participants $4 \& 5$ ).

The participants also described situations where the parents will prioritise relationships with new romantic partners over their relationships with the adolescents (participants 1 \& 2). This often results in neglecting, abusing or abandoning the adolescent "in order to ensure that the new partner is happy" (participant 1).

Parents or adults may also fail to recognise the adolescents' emotional needs, particularly around bereavement or loss experiences, where the natural "anger" of a grieving adolescent may earn them "a criminal record" rather than adequate support (participant 1).

Participants expressed that neglect is more likely to occur where the adolescent-parent relationship is of poor quality and has been for some time: They typically see parents who have not developed close relationships with the adolescents from childhood (participants 4 \& 5). These parents, suddenly finding that the adolescents are "out of control" (participant 5), will often take the easy option and relinquish control over the adolescents (participant 1). The participants mentioned numerous occasions where the adolescent-parent relationships breakdown completely that the parents decide that the adolescent can no longer stay at home (e.g. participants $2 \& 4$ ), the majority of these adolescents become homeless, which, in our participants' experiences, places the adolescents at more risk and disadvantage (participant 2), as well as being the ultimate form of neglect.

\section{Neglect and abuse}

The participants deal with both neglect and abuse, which present themselves in varying manifestations in their experiences. 


\subsection{The relationship between neglect and abuse}

Participants' highlighted that neglect and abuse, necessarily, coexist: "you can't really have...abuse without neglect [or]...neglect without abuse" (participant 3), and the worse one gets, the worse the other is likely to become (Figure 1). This coexistence was also depicted as overlapping (of circles, participant 5, Figure 2). Here, neglecting parents may also abuse the adolescents, or, the neglect may extend to failing to safeguard against abuse, to notice it, or to intervene to stop it (e.g. participants $2 \& 5$; Figure 2).

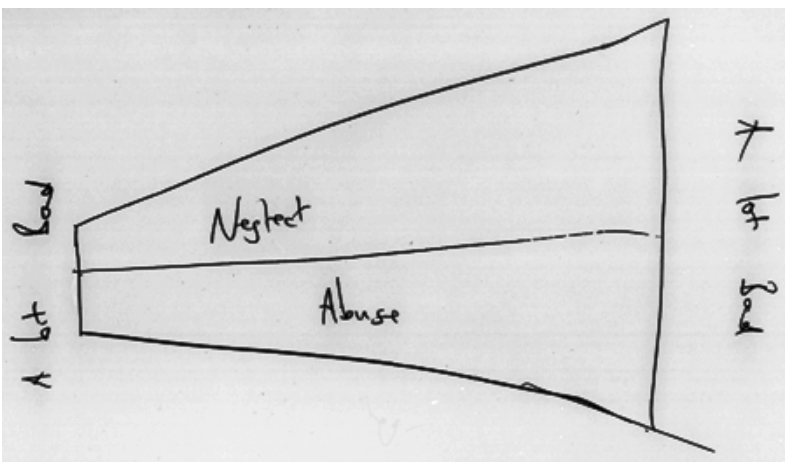

Figure 1. Participant 3's second diagram to illustrate how neglect and abuse may coexist and how they are likely to get worse (from a bit to a lot bad) almost in synchrony.

An alternative view is that neglect may "become" abuse, depending on its impact on adolescents' wellbeing: if neglecting to feed leads to starvation, or, if emotional neglect leads to maladjustment, then these are forms of abuse (participant 1). More specifically, participants expressed that severe neglect is likely to contain higher "proportions" of abuse (participant 3; Figure 3), and the "crossover" point (participant 3) between neglect and abuse is when neglect results in "significant harm" to the adolescent (participant 3).

\subsection{Neglect and abuse: More visible means more important?}

The participants revealed that in the neglect-abuse coexistence relationship, abuse is almost always more visible to society and to professionals than the "underlying" neglect (participant 5; Figure 2). This links well with the complexity of detecting neglect discussed above, and also seems to relate to the view that whereas all acts of neglect and abuse involve "betrayal" of adolescents, acts of abuse add "violation" to this betrayal (participant 2).

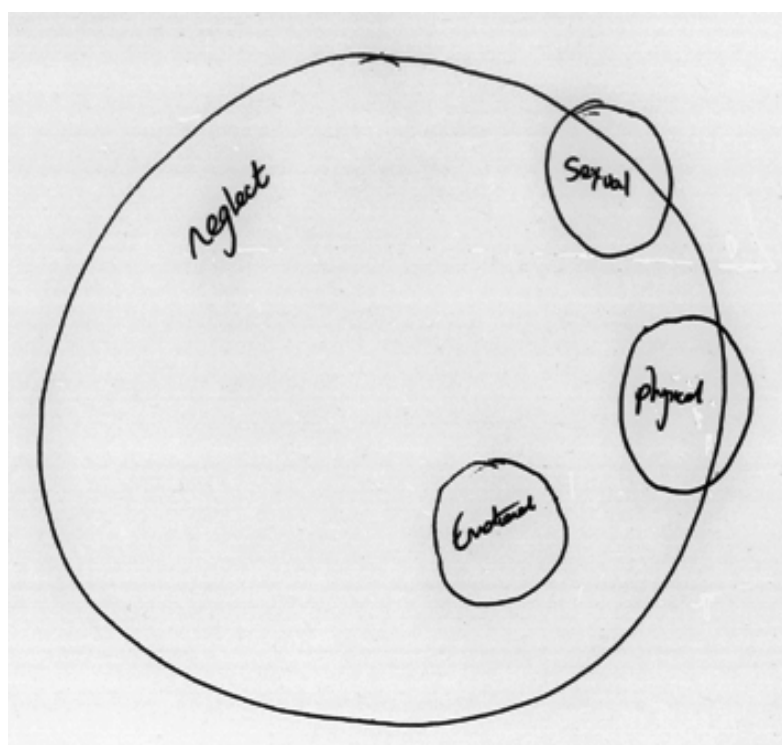

Figure 2. Participant 5's first diagram in which she explained that sexual, physical and emotional manifestations of abuse overlap with, and call attention to, neglect: "[N]eglect is the bigger thing and within that the other abuse happens, but it only comes to light in a child protection sense because of those two little circles and once people start looking at it, they will realise that something else is going on".

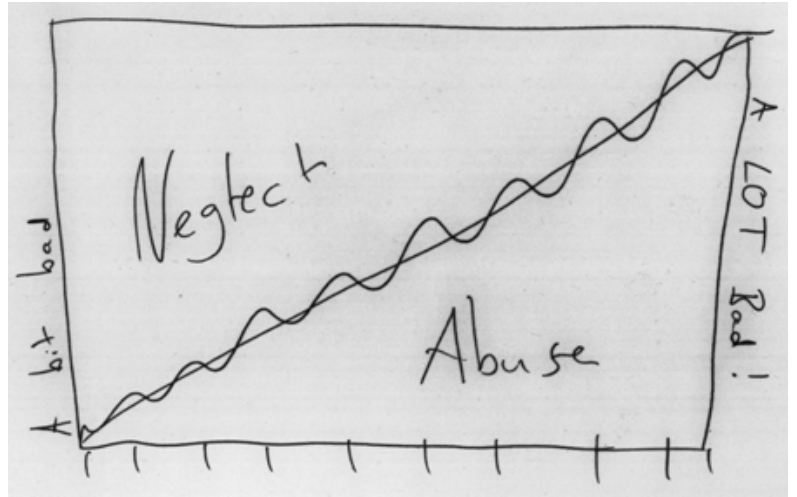

Figure 3. Participant 3's first diagram where increased levels of neglect, indicated by increasing 
the slope, contain grater proportions of abuse as the situation worsens from a bit to a lot bad.

Despite the greater visibility of abuse, participants also felt that neglect can be as damaging as or more damaging than abuse. Ongoing neglect can have a corrosive impact on adolescents' wellbeing, yet this sort of neglect is hard to detect as individual neglectful incidents do not meet professional thresholds for detection, compared to "oneoff' incidents of abuse (participant 5; Figure 4). So, on another level, neglect has yet to be regarded as equally damaging as abuse (participant 3).

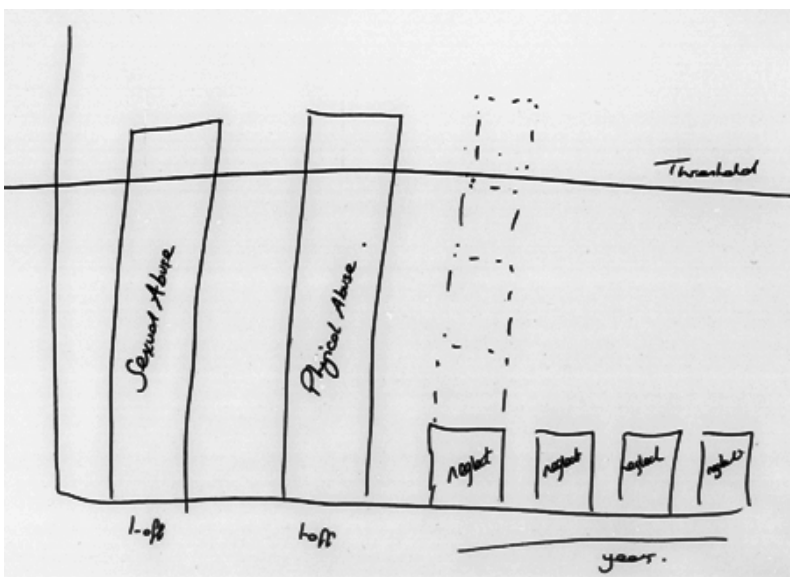

Figure 4. Participant 5's second diagram where "one-off" incidents of sexual or physical abuse clearly cross the threshold for detection, yet the ongoing neglect, illustrated by numerous incidents, and extending over the duration of "years" would not cross that detection threshold unless our systems of detection "stack[s]" these incidents (the dotted bar) which would then cross the threshold for professional detection.

\section{Dealing with Neglect}

Here we present some of the emotional consequences of dealing with neglect. This is followed by exploring some of the participants' professional preferences and stances which have taken shape through their experiences.

\subsection{The feeling professionals}

Participants expressed a range of emotions which accompany their dealing with neglect. All five spoke of a degree of frustration at the lack of resources, whether financial or human. On another level, the participants' expressed stronger emotions which, to us, highlight the fullness and authenticity of their experiences in dealing with neglect:

It's upsetting because...there's a child in all of this...all this horrendous stuff I can't imagine anyone who lives through it let alone a child. And you're worried...what is the outcome for that child? (Participant 5)

The tone of empathy present in this participant's words was further amplified by another participant whereby the experiences of dealing with neglect seems to include full access to the adolescents' emotional states: "if they don't have that [the love of their parents], then they feel like the most worthless unlovable person in the world" (participant 3 ).

The participants also expressed brighter and more positive emotions where they feel that working with this age group in particular can be an opportunity to "have an impact...and make a huge difference" (participant 2).

It will be recalled that at the outset $\mathrm{EH}$ expressed that "as a scholar, his interest in the process and method of investigation was stronger than his interest in the [neglect] phenomenon being investigated." However, this changed. Hearing about certain manifestations of neglect in the course of the interviews has had an emotional impact on EH. Being thus immersed in the experiences of the participants as a researcher, and as an embodied, emotional human (e.g. Finlay, 2006; Langdridge, 2007) was rewarding. It allowed us to appreciate the depths of the participants' experiences and how their views and emotions shape, and are shaped by, these experiences. Empathy with the participants 
and their experiences changed EH's detached outlook. Empathy with the neglected adolescents changes and shapes the emotional states of the participants, leading them to experiences of frustration at shrinking resources (participant 2), and fear of becoming accustomed to, and not being shocked by neglect any more, or minimising (participant $3)$.

\subsection{Matters of practice}

It became apparent that the participants have their preferred methods of working. They expressed what can be interpreted as a preference for "analytic" over "mechanistic" ways of working (participant 1), where the emphasis is on the uniqueness of each case, rather than mechanistic adherence to standardised procedures. This echoes the participants' empathetic emotional responses discussed above. Participants seemed to value holistic approaches, where health, monetary, psychological and environmental needs of the adolescents and their families are all targeted simultaneously or in a timely fashion. They described such approaches as a "glimmer of hope" for neglected adolescents (participant 4).

Finally, the participants expressed what we interpret as 'acknowledging the importance of their roles within set boundaries and limitations'. The participants' support and the "consistent [and] stable" relationships they establish with neglected adolescents are "really important," (e.g. participants 2 \& 3). However, the participants acknowledge that these adolescents will still need secure and close "personal" relationships with caring adults, like family members:

they need that personal relationship...[a] person they can go to in an emergency...[or] go and stay overnight...if things get really rough or someone who can lend them 10 quid, or all the professional boundary stuff that we can't do and won't do cause it's not appropriate (participant 3)

Obviously we're an agency not a parent...it's a professional relationship but I think a lot of children and young people find the [professionals'] support...very important (participant 2)

Unbracketing the notion of how professional agencies are attempting to compensate for organic units like the family, we find these lines above illuminating: as participant 2 put it, "all of us really" are links in the "chain" of care, or neglect: families, schools, other agencies, and society at large.

\section{Discussion}

The themes we have presented reveal how adolescence neglect manifested itself in our participants' experiences. The participants saw neglect as a spectrum, which extends in time and which marks the life and environment of neglected adolescents. The participants also saw neglect as a selfperpetuating cycle, where a neglected generation is likely to neglect the following one (e.g. George, Harden, \& Lee, 2008), and where a history of neglect makes it hard for the adolescents to accept support, which in turn perpetuates the neglect. This latter point echoes previous findings: Bal, Crombez, Van Oost, and Debourdeaudhuij (2003) found that the portion of their sample who experienced the severest maltreatment were least likely to seek support, rather they were more likely to avoid it.

Some societal and professional factors made it hard for participants to detect neglect. Adolescents do not use the term neglect to describe their situations, and the currently circulated professional definition of neglect is deficient in specifying family and parenting circumstances necessary for identifying neglect. Importantly, it seems that society at 
large (and even some professionals) misattributes adolescents' externalising and internalising behaviours as signs of their being "older" and "more independent," rather than signs that neglect may already be too severe. Societal failure to appreciate that adolescents can be as vulnerable as younger children may thus complicate the detection of neglect in this age group.

Our participants described a web of complex factors which they linked to the occurrence of neglect, these included: parental substance misuse, health and mental health problems, and the poor quality of the adolescent-parent relationship in its numerous manifestations. Indeed, previous research findings suggest that these factors are likely to place neglected adolescents at further disadvantage in terms of becoming offenders or developing risky health habits (e.g. Bender, 2010; Clark et al., 2005; Flick \& Röhnsch, 2007; Haber \& Toro, 2009; Shin, Edwards, \& Heeren, 2009).

To further illuminate the nature and boundaries of the phenomenon of neglect, we used a somewhat novel method to encourage the participants to describe how neglect maybe related to the phenomenon of abuse, given how both are repeatedly mentioned together in academic and professional literature and practice. The relationship between the two phenomena was interpreted in terms of necessary coexistence; coexistence in the sense of overlapping; and becoming, where neglect can become abuse, depending on the severity of the damage it causes. This latter notion lends support to earlier findings that severe neglect and abuse may lead to similar consequences for adolescents such as risktaking, and disturbed externalising and internalising behaviours and thoughts (Farber \& Joseph, 1985). The participants also described how the status of both phenomena is closely linked to their detectability or visibility, but not as closely linked to how damaging they can be. Typically, underdetected, equally-damaging, on-going neglect does not attract as much societal or professional attention as single incidents of abuse.

When investigating the relationship between abuse and neglect in our participants' experiences, we believe that asking participants to provide diagrammatic, as well as linguistic, descriptions and interpretations was largely successful and well-suited to the nature of the topic being explored. This rarely-used tool allowed the participants to extend their interpretative processes beyond language. The participants created revealing visual metaphors to express complex and intricate aspects of the neglect-abuse relationship.

We believe that integrating a complete reflexive process of bracketing and unbracketing, with the interpretative process, has allowed for greater transparency in our analyses. This, we hope, allows our participants and readers to fully engage with our output. This reflexivity has also allowed us a rich opportunity for learning, not only about the phenomenon we investigated, but about ourselves. Active reflexivity allowed $\mathrm{EH}$ sharing in the emotional experiences of the participants as an embodied and emotional human, which allowed us better appreciation of participants' experiences. This reflexivity has also allowed us to experience the fusion of our horizon with that of our participants (Gadamer, 1960), during and after the interviews. That is, engaging with our participants' experiences allowed us to reappraise our bracketed stances and share the participants' view point (Thomas \& Pollio, 2002). To illustrate, EH began this journey with doubts about the effectiveness of professional agencies attempting to compensate for the failings of organic units, like the family. Now, on the fused interpretative horizon, we see that thinking 
along the lines of a dichotomy between organic versus professional provision of care is limiting and can only encourage a bleak outlook. Neglect is a society-wide issue which requires a society-wide involvement.

Langdridge (2007) highlighted that phenomenological psychology faces accusations of being "politically naïve" ( $p$. 164) as it fails to attend to the socio-cultural and political backgrounds of investigations. It was clear to us that this piece of research coincides with professional and political interest in neglect and is linked to sociopolitical notions of accountability. It also coincides with a difficult financial climate which can make professionals, like our participants, uneasy or perhaps defensive when talking about their experiences and roles. We explained clearly to our participants that this investigation has no evaluative or judgemental agenda or remit; it is only an attempt at exploring the phenomenon of adolescence neglect through their experiences. We thus recommend that this paper is used as such. The only desirable outcomes of disseminating this work are fuelling a constructive discourse between interested academics and professionals, and enhancing a collective understanding and acceptance of our responsibility as a society to care for our young.

What do our findings say about practice? We feel that analytic professional functioning (e.g. participant 1), is a suitable match to the complexity of detecting adolescence neglect. Analytic approaches seek the history, "the root," "the reasons," (participant 5) and the meaning of neglect - the uniqueness of each case. Such an approach seems, at least intuitively, adequate in detecting the neglect which can otherwise remain hidden behind the adolescents' responses to it, or remain less visible than abuse. We also feel that not minimising when dealing with neglect (e.g. participant 3; also Farmer \& Lutman, 2010) can fuel a rigorous analytic approach, which is genuinely caring. Regardless of how common the manifestations of neglect are, or how often they are encountered, we should "not [be] forgetting the fact that it really shouldn't be, ever, happening, at all" (participant 3 ).

Future investigations may wish to expand our findings by recruiting frontline caseworkers, or indeed neglected adolescents, or members of their families. Recruiting adolescents in future investigations may highlight different perspectives and enrich our current understanding. Some evidence suggests that when adolescents speak of their neglectful families, their perceptions may differ significantly from those of their caseworkers and other professionals. For instance, Gable (1998) found that adolescents expressed what can be described as more positive views about the quality of their families' functioning compared to their caseworkers.

In conclusion, we attempted to explore the phenomenon of adolescence neglect as it presents itself to a senior and experienced group of professionals. Our interpretative phenomenological analysis allowed us to accomplish this aim. Adolescence neglect is a complex phenomenon which can have mild or severe manifestations, and which is capable of perpetuating itself. Neglect in this age group can be difficult to detect and is linked to a complicated web of factors; some of these may serve to perpetuate neglect. We explored our participants' interpretations of how neglect and abuse can be related in their experiences, and this was, we believe, the first systematic attempt at mapping the relationship between these two phenomena. Finally, our participants expressed preferences for analytic and holistic professional approaches to dealing with neglect. 


\section{References}

Alerby, E. 2000: A way of visualising children's and young people's thoughts about the environment: A study of drawings. Environmental Education Research 6, 205-222.

Bal, S., Crombez, G., Van Oost, P., and Debourdeaudhuij, I. 2003: The role of social support in well-being and coping with selfreported stressful events in adolescents. Child Abuse and Neglect 27, 1377-1395.

Becker-Lausen, E., and Rickel, A.U. 1995: Integration of teen pregnancy and child abuse research: Identifying mediator variables for pregnancy outcome. The Journal of Primary Prevention 16, 39-53.

Bender, K. 2010: Why do some maltreated youth become juvenile offenders? A call for further investigation and adaptation of youth services. Children and Youth Services Review 32, 466473.

Clark, D.B., Thatcher, D.L., and Maisto, S. A. 2005: Supervisory neglect and adolescent alcohol use disorders: effects on AUD onset and treatment outcome. Addictive Behaviors 30, 1737-1750.

Crowley, T.J., Mikulich, S. K., Ehlers, K.M., Hall, S.K., and Whitmore, E.A. 2003: Discriminative validity and clinical utility of an abuse-neglect interview for adolescents with conduct and substance use problems. American Journal of Psychiatry 160, 1461-1469.

DSCF 2010: Working together to safeguard children: A guide to inter-agency working to safeguard and promote the welfare of children. Nottingham: DCSF Publication.

Eatough, V., and Smith, J.A. 2008: Interpretative phenomenological analysis. In Willig, C. and Stainton-Rogers, W., editors, The Sage handbook of qualitative research in psychology. London: Sage.

Farber, E.D., and Joseph, J.A. 1985: The maltreated adolescent: patterns of physical abuse. Child Abuse and Neglect 9, 201-206.

Farmer, E., and Lutman, E. 2010: Case management and outcomes for neglected children returned to their parents: a five year follow-up study. Department for Education Research Report 214.
Fergusson, D.M., Boden, J.M., and Horwood, L.J. 2008: Exposure to childhood sexual and physical abuse and adjustment in early adulthood. Child Abuse and Neglect 32, 607619.

Finlay, L. 2006: The body's disclosure in phenomenological research. Qualitative Research in Psychology 3, 19-30.

Flick, U., and Röhnsch, G. 2007: Idealization and neglect - health concepts of homeless adolescents. Journal of Health Psychology 12, 737-749.

Gable, S. 1998: School-age and adolescent children's perceptions of family functioning in neglectful and non-neglectful families. Child Abuse and Neglect 22, 859-867.

Gadamer, H.G. 1960: Truth and method. New York: Seabury.

Gearing, R.E. 2004: Bracketing in research: A typology. Qualitative Health Research 14, 1429-1452.

George, R.M., Harden, A., and Lee, B.J. 2008: Consequences of teen childbearing for child abuse, neglect, and foster care placement. In Hoffman, S.D. and Maynard, R.A. editors, Kids having kids: economic costs and social consequences of teen pregnancy. Washington D.C.: Urban Institute Press.

George, S.R., and Thomas, S.P. 2010: Live experience of diabetes among older, rural people. Journal of Advanced Nursing 66, 1092-1100.

Haber, M.G., and Toro, P.A. 2009: Parentadolescent violence and later behavioural health problems among homeless and housed youth. American Journal of Orthopsychiatry 79, 305318.

Hall, D., and Williams, J. 2008: Safeguarding, child protection and mental health. Archives of Disease in Childhood, 93, 11-13.

Harkness, K.L., Bruce, A.E., and Lumley, M.N. 2006: The role of childhood abuse and neglect in the sensitization to stressful life events in adolescent depression. Journal of Abnormal Psychology 115, 730-741.

Harkness, K.L., Lumley, M.N., and Truss, A.E. 2008: Stress generation in adolescent depression: The moderating role of child abuse 
and neglect. Journal of Abnormal Child Psychology 36, 421-432.

Hicks, L. and Stein, M. 2010: Neglect Matters. Nottingham: DCSF Publication.

HM Government 2006: Working Together to Safeguard Children: A guide to inter-agency working to safeguard and promote the welfare of children. London: The Stationery Office.

Howes, C., and Espinosa, M.P. 1985: The consequences of child abuse for the formation of relationships with peers. Child Abuse and Neglect 9, 397-404.

Jenny, C., and Isaac, R. 2006: The relation between child death and child maltreatment. Archives of Disease in Childhood 91, 265-269.

Langdridge, D. 2007: Phenomenological psychology theory, research and method. Essex, England: Pearson Education Limited.

Lev-Wiesel, R. 1998: Use of drawing technique to encourage verbalization in adult survivors of sexual abuse. The Arts in Psychotherapy 25, 257-262.

Merleau-Ponty, M. 1962: The phenomenology of perception. New Jersey: The Humanities Press.

Polkinghorne, D.E. 1989: Incarnate phenomenological reflection. Theoretical and Philosophical Psychology 9, 46-51.

Ramm, A. 2005: What is drawing? Bringing art into art therapy. International Journal of Art Therapy 10, 63-77.

Rolls, L., and Relf, M. 2006: Bracketing interviews: Addressing methodological challenges in qualitative interviewing in bereavement and palliative care. Mortality 11, 286-305.

Rytterström, P., Cedersund, E., and Arman, M. 2009: Care and caring culture as experienced by nurses working in different care environments: A phenomenologicalhermeneutic study. International Journal of Nursing Studies 46, 689-698.

Shapiro, K.J. 1985: Bodily Reflective Modes: A Phenomenological Method for Psychology. Durham, NC: Duke University Press.

Shin, S.H., Edwards, E.M., and Heeren, T. 2009: Child abuse and neglect: relations to binge drinking in the national longitudinal study of Adolescence Health AddHealth Study. Addictive Behaviors 34, 277-280.
Smith, C.A., Ireland, T.O., and Thornberry, T.P. 2005: Adolescent maltreatment and its impact on young adult antisocial behavior. Child Abuse and Neglect 29, 1099-1119.

Smith, J.A., and Osborn, M. 2003: Interpretative Phenomenological Analysis. In Smith, J.A., editor, Qualitative psychology - A practical guide to research methods. London: Sage.

Sullivan, T.P., Fehon, D.C., Andres-Hyman, R.C., Lipschitz, D.S., and Grilo, C.M. 2006: Differential relationships of childhood abuse and neglect subtypes to PTSD symptom clusters among adolescent inpatients. Journal of Traumatic Stress 19, 229-239.

Swenson, C.C., Schaeffer, C.M., Henggeler, S.W., Faldowski, R., and Mayhew, A.M. 2010: Multisystemic therapy for child abuse and neglect: A randomized effectiveness trial. Journal of Family Psychology 24, 497-507.

Thomas, S.P., and Pollio, H.R. 2002: Listening to patients: a phenomenological approach to nursing research and practice. New York: Springer.

Van Manen, M. 1990: Researching Lived Experience - human science for an actions sensitive pedagogy. New York: State University of New York Press.

Wekerle, C., Leung, E., Wall, A., MacMillan, H., Boyle, M., Trocme, N., and Waechter, R. 2009: The contribution of childhood emotional abuse to teen dating violence among child protective services-involved youth. Child Abuse and Neglect 33, 45-58.

Williams, N.R., Lindsey, E.W., Kurtz, P.D., and Jarvis, S. 2001: From trauma to resiliency: Lessons from former runaway and homeless youth. Journal of Youth Studies 4, 233-153.

Zuravin, S.J., and Di Blasio, F.A. 1992: Childneglecting adolescent mothers: How do they differ from their normal treating counterparts? Journal of Interpersonal Violence 7, 471-489.

\section{Acknowledgments}

The authors would like to thank members of the Southampton Safeguarding Children Board (SSCB) for their support and input. We thank the participants for their time and valuable contributions. 
At the time of conducting this research FLB was funded by a fellowship from Arthritis Research UK (grant number 18099).

\section{Disclaimer}

This research was requested by the Southampton Safeguarding Children Board (SSCB) and carried out as part of the first author's doctoral training. No financial support, or any form of rewards were offered by the SSCB. The original data are available should anyone wish to check, question or challenge the information reported. Any opinions expressed in this report are those of the authors and do not necessarily reflect the views of the SSCB. 